\title{
PANORAMA GLOBAL DA COMUNICAÇÃO COMUNITÁRIA COMO AÇÃO POLÍTICA PERIFÉRICA
}

\section{GLOBAL OVERVIEW OF COMMUNITY MEDIA AS PERIPHERAL POLITICAL ACTION}

\section{Leonardo CUSTÓDIO ${ }^{1}$}

Resumo: Como processos de comunicação entre populações de baixa renda e/ou marginalizadas ocorre em regiões diferentes do mundo? Propondo e usando a noção de "ação política periférica", este artigo - uma análise crítica através de revisão bibliográfica - apresenta características políticas de práticas de comunicação comunitária na América Latina, América do Norte, Europa, África, Ásia e Oceania. O objetivo central é demonstrar que apesar das diferenças entre os contextos sociais e históricos, as práticas de comunicação comunitária pelo mundo são parte do processo de luta popular não só por espaços de fala, mas por transformação social e influência política.

Palavras-chave: Comunicação Comunitária; Ação Política Periférica; Cidadania.

Abstract: How do processes of communication among low-income and/or marginalized populations occur in different regions of the world? Proposing and using the notion of "peripheral political action", this article - a critical analysis based on literature review - presents political characteristics of community media practices in Latin America, North America, Europe, Asia, Africa and Oceania. The main objective is to demonstrate that despite the contextual and historical differences, community media practices around the world are part of people's struggles not only for raising voices, but to promote social change and political influence.

Keywords: Community Media, Peripheral Political Action, Citizenship.

Leonardo Custódio é Doutor em Ciências Sociais pela Escola de Comunicação, Mídia e Teatro (CMT) na Universidade de Tampere, na Finlândia. Sua pesquisa tem se concentrado nos processos de mobilização e engajamento de jovens de baixa renda em práticas de midiativismo no Brasil e no mundo. Contato: leonardo.custodio@uta.fi, lecczz@gmail.com e www.leocustodio.com. 


\section{míDiA \\ ecO DiAno}

\section{Introdução}

No Brasil, a comunicação comunitária é um processo de articulação, mobilização e diálogo entre a população de baixa renda e marginalizada na base dos movimentos populares (ver PAIVA, 2003; PERUZZO, 1998; ESTEVES, 2004). Mas como estas práticas de engajamento cidadão através dos meios de comunicação se caracterizam em outros países? A partir da noção original de ação política periférica, este artigo apresenta características políticas da comunicação comunitária em regiões diferentes do mundo. O objetivo central é demonstrar que apesar das diferenças entre os contextos sociais e históricos, existem elos essenciais que unem comunicadores comunitários locais em um movimento global. As práticas de comunicação comunitária pelo mundo são parte do processo de luta popular não só por espaços de fala, mas por transformação social e influência política.

Neste artigo, apresento algumas características políticas da comunicação comunitária no Brasil e em alguns países da América Latina, América do Norte, Europa, África, Ásia e Oceania. Meu objetivo é demonstrar que apesar das diferenças entre as sociedades, a comunicação comunitária se caracteriza como ação política periférica em todos os contextos. Primeiro, faço uma breve apresentação da diversidade conceitual em torno das práticas de comunicação comunitária. Em seguida, periferia é definida não só como espaços urbanos heterogêneos que historicamente sofrem com a precariedade de serviços públicos, com a condição predominante do subemprego e com a violência sobretudo em sociedades desiguais como a brasileira (BONDUKI; ROLNIK, 1979; PERLMAN, 2010; SOUZA, 2009; CUSTODIO, 2016), mas também como metáfora para a situação de exclusão e/ou discriminação de grupos marginalizados dos espaços legitimados de fala (ex.: canais de mídia) e esferas de poder (FRASER, 1992; WARNER, 2002) incluindo em países comumente tratados como "desenvolvidos" ${ }^{2}$. Por

2 Apesar de críticas ao uso do termo "periferia" em análises sobre a condição social e política de populações de baixa renda no Brasil contemporâneo (ex.: TANAKA, 2006), o termo mantém grande popularidade não só entre movimentos sociais urbanos de baixa renda (que o utilizam como uma espécie de identidade comum), mas também por indicar a persistência da exclusão de certos grupos sociais dos centros materiais e simbólicos de poder social e político em contextos urbanos distintos ao redor do mundo. 


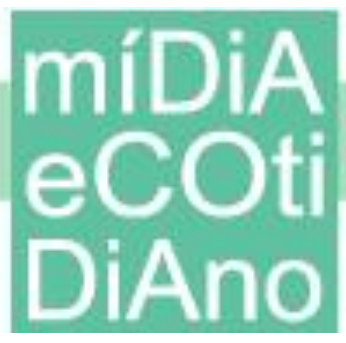

fim, tento mostrar que a essência política e periférica é um elo que une comunicadores comunitários em todos os continentes.

\section{Pontes conceituais para comparar práticas de comunicação comunitá ria}

Quando moradores do conjunto de favelas da Maré, no Rio de Janeiro, folheiam o jornal O Cidadão provavelmente eles não imaginam estar participando de uma ação política. Em geral, a palavra "política" faz as pessoas franzirem a testa imaginando candidatos em campanha ou a corrupção dos partidos. Mas política é muito mais do que isso. Quando os jornalistas voluntários de O Cidadão escrevem sobre histórias e moradores da Maré, divulgam eventos culturais, apresentam oportunidades de emprego e avaliam serviços públicos na favela, eles estão fazendo política. Nesta política do cotidiano (ALVAREZ et al, 2001), criam-se espaços de informação, diálogo e envolvimento de cidadãos em processos de compartilhamento de conhecimento e transformação social. Nas favelas, essas ações políticas através da comunicação são parte das reações populares contra consequências da desigualdade social: o preconceito, a falta de saneamento básico, a baixa qualidade da educação e saúde públicas, a falta de espaços de lazer e cultura, e a violência urbana.

O Cidadão é apenas um exemplo entre as incontáveis práticas de comunicação comunitária como ações políticas nas periferias brasileiras. Do Norte ao Sul, moradores, associações, organizações não-governamentais (ONG) e outros indivíduos e grupos exercem o direito de se comunicar para se fazerem ouvir e mobilizar mais pessoas em lutas pelo direito de ter direitos humanos e civis respeitados (ALVAREZ et al, 2001). Dizer exatamente quantos casos de comunicação comunitária existem no Brasil é impossível. Existem algumas estimativas. Por exemplo, segundo o Ministério das Comunicações, existem mais de 4,6 mil rádios comunitárias autorizadas no país. Mas esse número não é exato. Como contar, por exemplo, as emissoras que exercem função comunitária sem a autorização burocrática? E aquelas, como a Rádio Santa Marta (Rio de Janeiro), que foram forçadas a esperar o processo burocrático de licenciamento em silêncio? Os casos existentes, os que deixaram de existir e os não contabilizados 


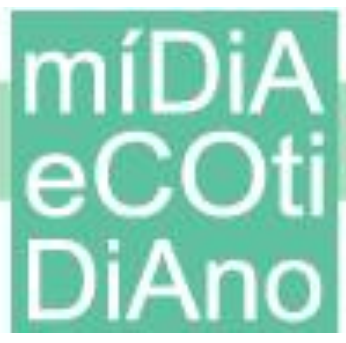

demonstram a diversidade de esforços na busca por formas de colocar cidadania em prática a partir da comunicação.

Essa diversidade também aparece em pesquisas acadêmicas cada vez mais recorrentes sobre comunicação comunitária (DORNELLES, 2007; PERUZZO, 2008). Por sua origem na base dos movimentos sociais, alguns autores falam de "comunicação popular" (PERUZZO, 1998). Por não fazerem parte dos grandes conglomerados de comunicação e em grande parte se contrapor a eles, outros autores falam em “comunicação alternativa" (FESTA; SILVA, 1986) ou "comunicação contrahegemônica" (MORAES, 2010). Por envolverem cidadãos, também se fala de “comunicação participativa” (PERUZZO, 2006) ou "mídia cidadã”. Estas práticas também são chamadas de "mídia/comunicação comunitária" por se relacionarem a um espaço geográfico específico ou a grupos de interesses que se caracterizam como comunidade (cf. PAIVA, 2003). A diversidade de conceitos também acontece nos debates internacionais. Em inglês, por exemplo, temos community media (HOWLEY, 2005), participatory media (CARPENTIER, 2011), alternative media (ATTON, 2002), radical media (DOWNING, 2001), citizens' media (RODRIGUEZ, 2001; 2011), grassroots media (GILLMOR, 2004) e tantos outros conceitos.

Em termos acadêmicos, a diversidade conceitual é bem-vinda. Afinal, conceitos nos ajudam a pensar realidades ou ações por pontos de vista diferentes. Mas tantos nomes também confundem e geram o risco de discutirmos tão conceitualmente a ponto de nos distanciar das práticas que queremos compreender (RODRIGUEZ et al, 2014). Decidi usar o termo "comunicação comunitária" porque é assim que a maioria dos midiativistas de favelas (CUSTÓDIO, 2016), comunicadores populares e jornalistas comunitários tendem a se referir às suas próprias ações. Com essa escolha, é possível explorar os conceitos de "comunicação comunitária" e "community media" como pontes teóricas para comparar práticas brasileiras com as de outros países. (cf. PAIVA et al, 2013) 


\section{"Periferia é periferia em qualquer lugar"}

Uma das maneiras de pensar as características políticas da comunicação comunitária em contextos diferentes é através da ideia de periferia. O verso da música "Periferia é Periferia"3 do grupo de rap Racionais MCs oferece essa possibilidade. Apesar de falar das periferias do Brasil, os Racionais MCs nos fazem refletir sobre o fato de que em todas as sociedades do mundo, pessoas sofrem as consequências da desigualdade social. Nestes contextos, indivíduos e grupos agem coletivamente para gerar mobilização, trocar conhecimento e influenciar os espaços centrais de debate e ação política. Ao mesmo tempo, esta música dá margem para que reflitamos sobre como as lutas periféricas se assemelham como ações políticas independente do contexto onde elas ocorram. Assim, para a reflexão sobre comunicação comunitária, podemos pensar a noção de periferia não só como espaços urbanos heterogêneos que historicamente sofrem com a precariedade de serviços públicos, com a condição predominante do subemprego e com a violência sobretudo em sociedades desiguais como a brasileira (BONDUKI; ROLNIK, 1979; PERLMAN, 2010; SOUZA, 2009; CUSTODIO, 2016), mas também como metáfora para a situação de exclusão e/ou discriminação de grupos marginalizados dos espaços legitimados de fala (ex.: canais de mídia) e esferas de poder (FRASER, 1992; WARNER, 2002) incluindo em países comumente tratados como “desenvolvidos". Com essa definição em mente, periferia aparece como uma característica em comum entre as lutas de populações de baixa-renda que contestam "as coisas como elas são" e que tentam se estabelecer como grupos sociais que tem o poder de influenciar políticas públicas e outros aspectos da sociedade que afetam seus cotidianos (cf. LUKES, 1980).

Pelo ponto de vista das lutas políticas, temos pelo menos dois espaços centrais de poder: o espaço de fala nas mídias e as esferas de decisão por políticas públicas. Nos dois casos, pessoas e grupos que participam dessas esferas têm condições de influenciar em maior ou menor grau a nossa vida em sociedade. Assim, a comunicação comunitária

\footnotetext{
3 Para acessar a letra completa da música dos Racionais MCs, ver <http://www.vagalume.com.br/racionais-mcs/periferia-e-periferia.html>. Acesso em 18/11/2016.
} 


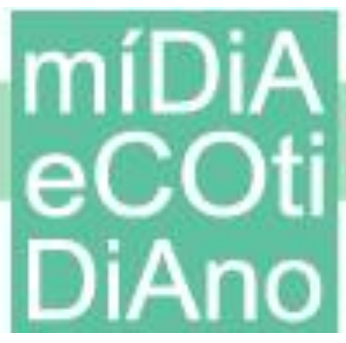

representa luta política pela criação e/ou acesso aos espaços de fala e de influência no debate sobre políticas públicas. As lutas populares pelo direito de se comunicar variam de um lugar para o outro. Mas esses lugares têm, em comum, as ações políticas periféricas - como a comunicação comunitária - para se fazer incluir ou criar suas próprias esferas de poder a partir da comunicação.

No Brasil, a comunicação comunitária tem características políticas diversas. Em alguns casos, essas lutas são contra representações negativas na grande mídia. Pense nas favelas, por exemplo. Muitos moradores se sentem estigmatizados e criminalizados na mídia. Às vezes, aparecem como os "pobres que se matam de trabalhar, mas são felizes". Outras vezes aparecem como "malandros machistas" ou "negras fogosas". No noticiário é pior. Moradores de favelas aparecem como autores e vítimas da violência ou como coniventes ou cúmplices de crimes. A mídia não só contribui para a perpetuação desses preconceitos, mas os reforça e legitima. Por isso, contestar estes preconceitos ao fazer mídia de forma diferente é uma ação política. (CUSTÓDIO, 2016, p. 59-81)

Além de contestar discursos e construir representações próprias de si, comunicadores comunitários também se engajam em mobilização popular. O Cidadão da Maré, por exemplo, organiza e participa de debates em favelas para discutir políticas públicas e qualidade de vida. Os comunicadores também participam de manifestações dentro e fora das favelas que chamem atenção da sociedade para as dificuldades e violações de direitos humanos no cotidiano mareense. O Cidadão também promove um curso de comunicação comunitária para compartilhar conhecimentos e ampliar ou renovar a equipe de voluntários do jornal. Quer dizer, a comunicação comunitária não é apenas uma questão de fala alternativa à grande mídia. É também - e principalmente um conjunto de ações políticas que fazem das periferias não só espaços de contraposição aos centros de poder, mas centros de geração de poder popular a partir da comunicação.

Em resumo, definir a comunicação comunitária como ação política periférica não é só uma questão geográfica. Tratam-se de lutas encampadas nas periferias das esferas de poder. São ações que visam tornar relevante o poder e a influência política que surge 


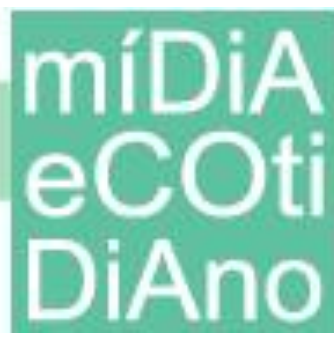

dos espaços e posições periféricas. Por isso, a comunicação comunitária é um fenômeno global. Afinal, periferia é periferia em qualquer lugar.

\section{Comunicação comunitária como ações políticas periféricas ao redor do mundo}

Para apresentar a comunicação comunitária em regiões diferentes do mundo como ações políticas e periféricas, esta seção é organizada por regiões: América Latina, América do Norte, Europa, África, Ásia e Oceania. Descrever e analisar todas as práticas em todas essas regiões seria uma tarefa impossível. Por isso, reviso alguns estudos que lidam com community media e apresento alguns exemplos históricos e/ou contemporâneos para ilustrar suas características políticas.

\section{América Latina}

Na América Latina, algumas peculiaridades que influenciam a existência de práticas de comunicação comunitária são: (a) o fato de serem antigas colônias onde (b) os povos nativos foram subjugados pelos colonizadores portugueses e espanhóis. Parte significativa do processo de colonização foi conduzido com a força (c) do trabalho escravo. No período recente, (d) os diversos regimes autoritários e (e) a desigualdade social e econômica reforçaram o posicionamento da maior parte das populações nativas e descendentes de escravos nas periferias tanto das cidades quanto da representação política.

Todos estes fatores juntos, em maior ou menor grau de influência, contribuíram para o modo como a comunicação comunitária é feita na América Latina. Muitos autores consideram como os primeiros exemplos de comunicação comunitária no mundo a Rádio Sutatenza (1947, Colômbia) e as Rádios Mineiras (1949, na Bolívia) (GUMUCIO-DAGRON, 2001). Os dois casos representam esforços de comunidades locais para diminuir os impactos da desigualdade e a distância entre trabalhadores e populações pobres e as esferas de poder, a partir da comunicação.

A Rádio Sutatenza foi criada por um padre no vilarejo de mesmo nome na Colômbia para promover a alfabetização entre trabalhadores rurais. Ao ser transferido para a paróquia local, ele percebeu que a maioria das pessoas eram analfabetas. O alcoolismo e a violência também eram grandes problemas. Então o padre resolveu criar 


\section{míDiA \\ ecO DiAno}

maneiras de mobilizar a comunidade. Primeiro, produziu peças de teatro e filmes com a participação dos moradores. Em seguida, com um pequeno transmissor, começou a usar o rádio como instrumento de alfabetização. Neste processo, os moradores participavam da programação com suas músicas e temáticas de interesse comunitários. A Rádio Sutatenza chamou atenção do alto-clero da igreja e dos governantes. Com apoio local e de organizações internacionais, a rádio virou um programa nacional de alfabetização que durou até 1990 quando encerrou as atividades por falta de recursos.

As Rádios Mineiras foram criadas por trabalhadores de minas bolivianas. Com recursos tecnológicos precários, trabalhadores criaram uma estação de rádio. Nela, as pessoas ouviam informações trabalhistas e músicas locais. A partir dos sindicatos, outras rádios foram criadas em outros distritos. Além de informar sobre direitos trabalhistas, as rádios também funcionavam como correios e espaços de valorização do folclore indígena. A rede de rádios também agiu como resistência à repressão militar. Em 1980, por exemplo, as rádios informaram os avanços das tropas militares contra as rádios e os sindicatos. Transmitindo em rede, as rádios mineiras informaram até o último minuto quando saiu do ar ao barulho de tiros no estúdio. Em anos seguintes voltaram a transmitir. Mas com o enfraquecimento da mineração estatal na década de 1980 e a migração dos trabalhadores para os centros urbanos, as rádios mineiras aos poucos deixaram de operar (Para uma revisão ampla destes e outros casos, ver GUMUCIODAGRON, 2001).

Nos dias de hoje, a essência política dos pioneiros da comunicação comunitária latino-americana permanece. $\mathrm{Na}$ aparente maioria dos casos, a comunicação comunitária acontece em centros urbanos nas favelas, barios e outras localidades onde se concentram populações de baixa renda. Em alguns casos, são processos comunicacionais criados por organizações não-governamentais (ONGs). Em outros, são moradores, associações locais ou grupos de amigos que criam canais de interação, mobilização e troca de conhecimentos através da comunicação. Nestes casos, fazer comunicação comunitária significa se envolver em processos pedagógicos, midiáticos e jornalísticos que contestem as consequências da desigualdade social e lutem por democracias de fato democráticas. 


\section{míDiA \\ eco DiAno}

América do Norte

Apesar de Estados Unidos e Canadá também terem problemas de desigualdade social originados na constante imigração e tráfico escravagista, a questão da disputa de classes não tem destaque central nos estudos atuais sobre comunicação comunitária (cf. HOWLEY, 2005). Lá, a questão da ação política periférica aparece na ênfase à produção de conteúdo local e alternativo às corporações de comunicação. $\mathrm{O}$ fator político aparece na exclusão de comunidades periféricas locais do sistema midiático dominado pelas grandes empresas de comunicação. Em outras palavras, "mídias comunitárias são intervenções populares e estratégicas na cultura midiática contemporânea comprometidas com a democratização das estruturas, formas e políticas midiáticas" (HOWLEY, 2005, p. 2, ênfase minha). Mesmo que abordem a questão dos direitos civis em seus discursos, na prática os estudos tendem a enfatizar a construção de um sentido de comunidade, solidariedade e cultura entre habitantes de uma determinada cidade ou região a partir de ações que criem alternativas às corporações no conteúdo das mídias.

Parte significante dos estudos sobre comunicação comunitária na América do Norte se concentra nas rádios. Uma das pioneiras foi a Rádio Pacífica, na Califórnia. Em 1949, quatro anos depois do fim da Segunda Guerra Mundial, um homem incomodado com a comercialização dos conteúdos das mídias corporativas mobilizou pessoas com ideias semelhantes para criar uma rádio que transmitisse conteúdos diversificados e que gerasse diálogo entre culturas, etnias e crenças diferentes. A rádio também era parte do movimento pacifista. Além da programação com música e informações locais, os programas discutiam criticamente assuntos anti-guerra. Para se manter, a Rádio Pacífica criou um sistema de financiamento pelos ouvintes que se tornou um modelo internacional entre rádios comunitárias (HOWLEY, 2005). Nos dias de hoje, a Rádio Pacífica enfrenta uma de suas piores crises administrativas, financeiras e produtivas ${ }^{4}$. Ainda assim, permanece como um dos exemplos mais reconhecidos de comunicação comunitária da América do Norte.

4 Para uma análise da Rádio Pacífica em Março de 2014, ver (em inglês): <http://www.laweekly.com/2014-03-20/news/left-wing-darling-pacifica-radio-is-sliding-into-theabyss/?showFullText=true >. Acesso em 18/11/2016. 


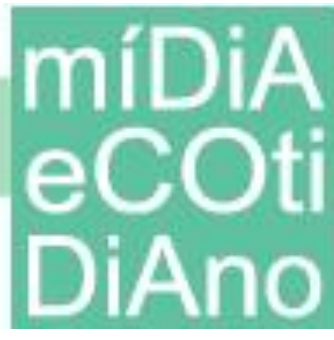

Mas também há estudos sobre comunicação comunitária impressa. Para alguns autores da região, um jornal comunitário é um tipo de publicação produzida pela própria população "com uma circulação abaixo de 50 mil que serve às pessoas que vivam juntas num espaço geográfico distinto com uma ênfase primária local sobre notícias, informações, esportes e publicidade" (LAUTERER, 2006, p. 1). Mas outros autores saem da definição geográfica de comunidade e incluem elos étnicos, profissionais ou ideológicos entre aqueles que produzem e consomem os meios (READER; HATCHER, 2012). Um exemplo é o circuito de jornais étnicos publicados pela e para as comunidades negras nativas ou imigrantes de Montreal, no Canadá (OJO, 2006). Os jornais foram criados a partir da percepção de invisibilidade e de exclusão destes grupos dos espaços dominantes na mídia. A característica destas ações como políticas periféricas aparece não necessariamente para questionar o status da democracia nos dois países, como na América Latina, mas na luta para criar espaços de fala e participação popular nos debates públicos.

\section{Europa}

A Europa é um continente diverso formado numa história milenar de conflitos políticos e guerras. Assim, uma apresentação da comunicação comunitária na Europa não pode ignorar, por exemplo, a complexidade geopolítica e econômica da região antes e depois da Segunda Guerra. O Sul europeu foi marcado por regimes autoritários (ex.: Itália, Espanha, Portugal, Grécia). A Europa Central (ex.: Alemanha, França, Holanda, Polônia) teve que se reconstruir. Ao mesmo tempo, tiveram que lidar com altos índices de imigração como ocorreu na Grã-Bretanha e nos países nórdicos (ex.: Noruega, Dinamarca, Suécia e recentemente Finlândia). Já o Leste Europeu (ex.: as antigas repúblicas soviéticas) e os Balcãs (ex.: a antiga Iugoslávia) tiveram conflitos internos que causaram o (res)surgimento de países independentes (ex.: Ucrânia, Lituânia, Letônia, Estônia, Sérvia, Croácia, Bósnia e Herzegovina, e Eslovênia) com a transição do sistema comunista para o capitalista.

Neste contexto, a comunicação comunitária aparece como formas de ações políticas que variam tanto entre lutas contra governos ditatoriais quanto por representações políticas, culturais e étnicas. Nesse sentido, podemos falar em três 


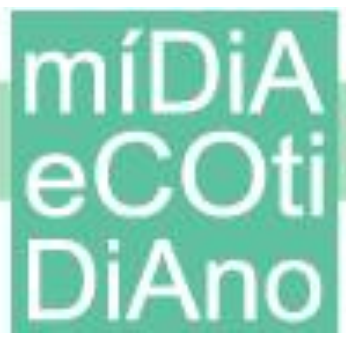

categorias de comunicação comunitária na Europa. Essas categorias não servem para dizer que estes são "os" tipos, mas "alguns" tipos de comunicação comunitária que existem ou já existiram no continente. Elas são: (a) resistência político-ideológica; (b) espaços étnicos e (c) valorização de culturas e cotidianos locais.

Exemplos de comunicação comunitária de resistência político-ideológica ocorreram nos anos 1960-1990 durante o processo de desconstrução do bloco comunista. Nestes casos, a característica periférica estava na luta de grupos políticos e civis por participação política ou resistência ao regime. Parte dos movimentos de resistência na República Checa (antes Checoslováquia) e na Polônia surgiram a partir de reações à censura comunicacional. Com um sentimento comunitário alimentado pela nacionalidade, publicações dissidentes e clandestinas alimentavam manifestações, greves e a circulação de informações contrárias ao controle Russo. (DOWNING, 2000). Outro exemplo foi a Rádio B92 que se tornou um exemplo de resistência ao regime ditatorial durante as guerras iugoslavas na década de 1990. A rádio formada por jovens opositores do regime comunista organizava e mobilizava protestos a partir das transmissões. Além disso, criava um circuito cultural de música e debate. (PLANSAK; VOLCIC, 2010).

A comunicação comunitária étnica se dá principalmente entre imigrantes e seus descendentes na Europa. Em diversos países existem rádios, jornais e revistas que representam culturas de grupos étnicos específicos. Estes grupos são periféricos tanto cultural quanto politicamente. Sua marginalização na sociedade também se reproduz nas redes comerciais e públicas de comunicação. Em alguns países, o número de mídias étnicas impressiona. Só na pequena Holanda, são mais de 150 mídias eletrônicas étnicas. Mais de 90 eletrônicas e impressas na Alemanha e, no recordista Reino Unido, chegam a mais de 100 periódicos, 15 rádios e 30 canais de televisão (MATSAGANIS; KATZ; BALL-ROKEACH, 2010). As mídias comunitárias étnicas também existem em lugares pouco prováveis como a Rússia. Grupos étnicos nativos do território russo usam impressos e redes sociais online para manter sua cultura, tradições e idiomas originais vivos diante da dominação cultural russa (CUSTÓDIO, 2011). 
A comunicação comunitária que valoriza culturas e cotidianos locais se refere às localidades geográficas. Na Finlândia, por exemplo, existe uma abundância do que chamaríamos de "jornais de bairro" no Brasil. Estes impressos geralmente focam em informações de utilidade pública e culturais de locais específicos. Na capital Helsinki, existem vários jornais comunitários apesar do Helsingin Sanomat, maior jornal do país, ser da cidade. Também há rádios comunitárias como a Rádio Helsinki. A rádio foi criada no ano 2000 para ser uma rádio comunitária que explorasse a diversidade musical e cultural da cidade. Em 2005, o Grupo Sanoma (que controla o Helsingin Sanomat) comprou a rádio, mas decidiu fecha-la em 2013 por prejuízos financeiros. Foi então que a campanha Save Radio Helsinki (Salve a Rádio Helsinki) mobilizou ouvintes nas redes sociais para pedir o não-fechamento da rádio. Poucos meses depois, um grupo de pessoas (jornalistas, empresários e celebridades) adquiriram a rádio para mantê-la funcionando com as ideias originais ${ }^{5}$.

\section{África}

A África foi o continente que mais sofreu com a exploração colonial e escravagista. A história de exploração natural e humana mais o descaso sócio-político de séculos deixaram sequelas que influenciam a característica política da comunicação comunitária na região. O continente africano é marcado pela desigualdade social visível no contraste da qualidade de vida e infraestrutura entre centros urbanos e as áreas pobres localizadas nas periferias das cidades e no campo. Pelo aspecto governamental, o continente é um mosaico formado por regimes ditatoriais e repúblicas pós-autoritárias sob ameaças constantes de golpes de estado e guerras civis. Há, ainda, os altos índices de pobreza, violência e outras dificuldades enfrentadas no cotidiano africano. Assim como na América Latina, as ações políticas periféricas não são apenas uma questão de se fazer ouvir, mas de combater e transformar situações de desigualdade social.

Nos países da África Ocidental (ex. Senegal, Mali, Gana, Nigéria), a maioria de sistemas de mídia nacionais são controlados por governos autoritários. Ainda assim, experiências de meios de comunicação (especialmente o rádio) e processos

Sobre a Rádio Helsinki, ler (em inglês): <http://yle.fi/uutiset/free-form_radio_helsinki_gets_lastminute_reprieve/6828996>. Acesso em 18/11/2016. 


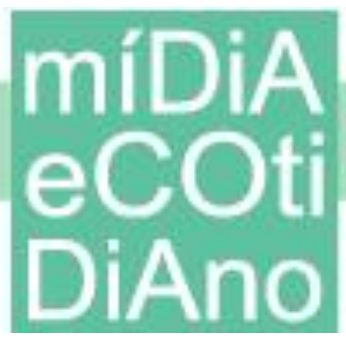

comunicacionais (ex. teatro, drama, música) para o desenvolvimento socioeconômico surgiram especialmente das regiões rurais nas décadas de 1960 e 1980. Porém, as rádios comunitárias controladas por populações locais ainda eram poucas se comparadas à maioria fomentada ou controlada por governos. Duas exceções eram a Rádio Ada e Rádio Comunitária Winneba, ambas em Gana. Elas tinham apoio de agências internacionais para promover o desenvolvimento local com transmissões nos idiomas da região. Estas rádios são importantes especialmente por transmitirem em idiomas locais e assim funcionarem como espaços de resistência cultural. (KARIKARI, 2000; AHADE, 2000)

No Leste (ex. Tanzânia, Quênia, Uganda, Somália) e no Sul (ex. África do Sul, Namíbia), o período de formação da comunicação comunitária aconteceu principalmente durante os movimentos populares contra regimes autoritários, como nas lutas contra o Apartheid na África do Sul. Além da demanda por participação popular nos processos políticos, estes movimentos buscavam novas formas de comunicação, associação e desenvolvimento contra a desigualdade social. Estes processos comunicacionais valorizam a tradição oral em peças teatrais, música e dança. Além disso, várias associações e iniciativas de rádios comunitárias surgiram na África do Sul, Quênia, Namíbia, Tanzânia, Uganda e Zâmbia. Estas iniciativas não só geravam informação, mas criavam processos educacionais e canais de interlocução entre populações de regiões diferentes. (WANYEKI, 2000). A semelhança destes processos com aqueles inspirados por Paulo Freire na América do Sul a partir da década de 1960 não é coincidência: a partir de diálogos internacionais promovidos pela UNESCO, as experiências latino-americanas se tornaram modelos de trabalho de base a partir da comunicação em vários países africanos e asiáticos.

Atualmente, a comunicação comunitária continua como uma forma de promover o engajamento político no cotidiano principalmente entre jovens pobres. Um exemplo parecido com o trabalho feito em favelas do Rio de Janeiro acontece em favelas de Nairóbi, no Quênia. As rádios Kock FM, Pamoja FM e Ghetto FM foram criadas por jovens moradores para mobilizar mudanças nos locais onde moram. As três rádios oferecem três tipos de programas: notícias, programas temáticos e músicas. Os temas 


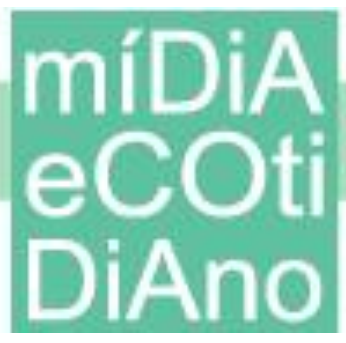

debatidos incluem uso de drogas, gravidez, violência doméstica e ociosidade. Os programas também informam sobre ações do governo e possibilidades de serviços ou assistência social. Neste processo, as rádios das favelas de Nairóbi não só têm se tornado referência local, mas também valorizado a identidade local aumentando a autoestima de moradores que em geral são criminalizados nas suas sociedades. (GUSTAFSSON, 2013).

\section{Ásia}

As questões políticas que mobilizam as práticas de comunicação comunitária na África se refletem na Ásia. Me refiro aqui especificamente às regiões sul (ex.: Índia, Bangladesh, Paquistão, Sri Lanka) e sudeste (ex.: Filipinas, Singapura, Indonésia, Tailândia, Vietnã) onde a maior parte da literatura sobre comunicação comunitária em inglês se concentra. Nestas regiões estão países que também sofreram com a exploração do período das colonizações. Este processo, completado por peculiaridades locais (ex. as castas na Índia) perpetuou a desigualdade social principalmente visível entre populações urbanas e rurais, mas também dentro das periferias urbanas. Como no Brasil, mas em condições muito mais precárias, as regiões pobres sofrem com falta de saneamento básico e serviços públicos de qualidade. Essa situação se torna ainda pior pela maioria de governos autoritários que centralizam o controle administrativo e não fazem muitos esforços para melhorar a qualidade de vida da maioria pobre das populações. Com algumas exceções (ex.: Índia, Filipinas), os governos também exercem um forte controle sobre as mídias, principalmente as eletrônicas.

Nestas circunstâncias, a comunicação comunitária acontece como práticas criativas que variam em níveis de qualidade e desenvolvimento dependendo do contexto onde se inserem. Alguns países possuem um cenário regulamentado para transmissões eletrônicas de comunicação comunitária. Na Índia, um forte movimento pela democratização da comunicação, durante os anos 1990, conseguiu influenciar a criação de políticas públicas para comunicação comunitária. Desde 2006, ONGs locais e outras organizações da sociedade civil podem operar rádios comunitárias. Mesmo assim, com restrições. Elas não podem transmitir noticiários, por exemplo. (SAEED, 2009) Nas Filipinas, a década de 1980 já apresentava um cenário significativo com 


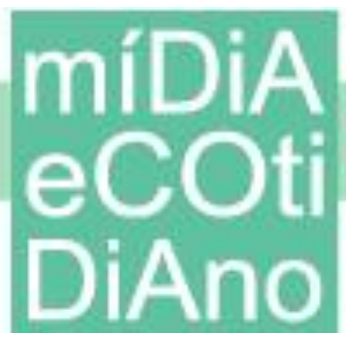

aproximadamente 400 rádios comunitárias, mesmo que a grande maioria tivesse interesses comerciais. Nos anos 1990, o projeto Tambuli, com apoio de organizações internacionais de desenvolvimento, ajudou na criação de dezenas de rádios. As populações de diversas vilas foram treinadas para que pudessem criar e manter suas próprias rádios a partir dos interesses locais. (TABING, 2000; PAVARALA; MALIK, 2007)

Porém, na maioria dos países do sul e sudeste da Ásia a comunicação comunitária é feita a partir de soluções mais artesanais e impressas devido sobretudo à censura e ao controle governamental dos meios. Os exemplos destas práticas de comunicação comunitária incluem ideias como um jornal escrito em quadro-negro no centro de uma vila, jornais mimeografados de pescadores ou comunidades rurais nas Filipinas. Há também performances teatrais e artísticas para comunicação, educação e desenvolvimento de base na Malásia e Indonésia. (TABING, 2000). Outro processo de comunicação comunitária envolve a produção de vídeos participativos. Um caso reconhecido internacionalmente é o da SEWA, uma organização sindical de mulheres autônomas numa região rural da Índia. A partir de uma oficina na década de 1980, participantes da SEWA passaram a produzir vídeos com as comunidades locais para informar, mobilizar a participação política local e criar canais de diálogos com autoridades governamentais. Desde então, a SEWA atua em vilas rurais e favelas urbanas promovendo diálogo e informação através dos vídeos. (GUMUCIO-DAGRON, 2001).

\section{Oceania}

Na Austrália e Nova Zelândia, há uma situação que combina as características europeias com aquelas das regiões colonizadas. Pelo vínculo político com o Reino Unido, os países são extensões culturais, políticas e econômicas da Europa Ocidental no Oceano Pacífico. Ao mesmo tempo, convivem com populações indígenas milenares que resistem principalmente à influência cultural e ao predomínio político dos colonizadores europeus. Na Nova Zelândia, os povos nativos mais representativos são os maoris. Na Austrália, há uma imensa diversidade de povos aborígenes. Nos dois países, os povos nativos se engajam na comunicação comunitária por lutas contra a criminalização de 


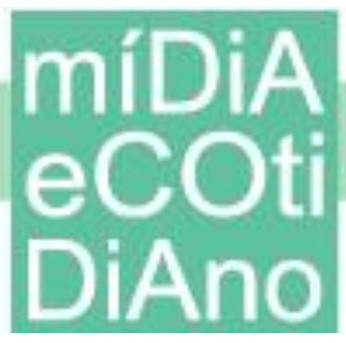

seus povos nas representações negativas que predominam nas mídias comerciais e públicas. Esta luta por representações positivas na mídia é parte de um movimento mais amplo de lutas por maior participação dos povos nativos nas decisões políticas dos países.

Nem toda comunicação comunitária na Oceania é feita pelos povos indígenas. Em um estudo sobre audiência da comunicação comunitária (MEADOWS ET AL., 2009), pesquisadores sugerem que a Austrália possui uma das maiores audiências de mídias comunitárias entre os países industrializados. Como o país possui imensa diversidade regional, muitas pessoas escolhem ouvir as produções locais em vez das rádios comerciais e públicas que transmitem nacionalmente. A escolha pelas mídias locais representa a busca por produtos da mídia que toquem músicas e produzam conteúdos locais além de apoiar às tantas culturas australianas. Então, de uma forma geral, as rádios comunitárias representam interesses de comunidades compreendidas a partir dos locais específicos de moradia.

Mas os estudos de comunicação comunitária na região tendem a enfatizar as ações dos povos nativos. A motivação dos povos nativos para fazer comunicação comunitária na Austrália é parecida com os grupos étnicos na Europa. "O descontentamento com a representação negativa de assuntos indígenas e o desejo de se apropriar das tecnologias de comunicação como forma de prestar serviços às comunidades" faz com que as mídias eletrônicas aborígenes - sobretudo o rádio - se tornem o setor que cresce mais rápido no país (MEADOWS; MOLNAR, 2002, p. 19). Desde a primeira metade do século XIX, os povos nativos da Austrália produzem jornais, folhetos e outros tipos de mídia impressa. Mas a partir da década de 1970 o fenômeno das rádios comunitárias foi impulsionado. Financiadas pelo governo federal, até 2007 existiam aproximadamente 107 emissoras indígenas na Austrália (MEADOWS, 2009). O processo de comunicação entre os maoris na Nova Zelândia foi parecido. Em meados do século XIX surgiram os primeiros impressos. Durante boa parte do século XX, maoris tinham concessões em emissoras nacionais neozelandesas. Somente após pressões populares nos anos 1970, os maoris hoje possuem rádios e canais de televisão controlados por eles mesmos apesar de financiados pelo governo da Nova Zelândia (HANUSCH, 2014). 


\section{Conclusão}

Em todos os continentes, pessoas e grupos sociais se apropriam dos meios de comunicação disponíveis não só para falar ou questionar as mídias dominantes, mas para criar suas próprias arenas de debates e troca de conhecimento em esforços constantes por poder e influência nas sociedades em que se encontram. Em alguns casos, o poder está na capacidade de representar culturas locais e/ou étnicas por si diante da atenção irregular ou completo descaso das grandes empresas de comunicação. Em outros, o poder está na resistência contra governos repressores ou contra a opressão sofrida no cotidiano como consequência das desigualdades sociais.

Ao pensar a comunicação comunitária pelo mundo como ações políticas periféricas é possível localizar práticas corriqueiramente vistas como pequenas e insignificantes em um fluxo constante e global de lutas por direitos e por espaços de participação política. A comunicação comunitária tem diversos nomes e formatos, mas acima de tudo carrega em si práticas que representam a busca constante por sociedades mais justas, igualitárias e plurais. A criação de espaços de fala na periferia dos sistemas de mídia dominados por corporações ou estados autoritários é, na verdade, apenas uma dimensão de lutas muito mais amplas e abrangentes por poder e por transformação social a partir da comunicação.

\section{Agradecimentos}

Agradeço à Escola de Doutorado em Estudos de Comunicação (VITRO) da Universidade de Tampere pelo apoio financeiro durante meus estudos de doutorado. Também agradeço à Professora Ana Lúcia Vaz por revisar versões preliminares deste artigo. Finalmente, agradeço aos colegas pelos comentários profundos e pertinentes durante o processo de revisão cega.

\section{Referências}

AHADE, Yao. The Development of Community Media in French-speaking West Africa. In BOAFO, Kwame (org.) Promoting Community Media in Africa. Paris: UNESCO, 2000.

ALVAREZ, Sonia E; DAGNINO, Evelina; ESCOBAR, Arturo (Orgs). Cultura e Política nos Movimentos Sociais Latino-Americanos (novas leituras). Belo Horizonte: Editora UFMG, 2001.

ATTON, Chris. Alternative Media. Londres: SAGE, 2002. 
BONDUKI, Nabil; ROLNIK, Raquel. Periferias: Ocupação do Espaço e Reprodução da Força de Trabalho. São Paulo: PRODEUR-FAUUSP/FAPESP, 1979.

CARPENTIER, Nico. Media and Participation: A Site of Ideological-Democratic Struggle. Chicago: Intellect, 2011.

CUSTÓDIO, Leonardo. Participatory Media as an Alternative Approach to Civic Action in Russia. Russian Journal of Communication, v. 4, n. 3-4, 2011.

CUSTÓDIO, Leonardo. Favela Media Activism: Political Trajectories of Low-Income Brazilian Youth. Tampere: University of Tampere Press, 2016.

DORNELLES, Beatriz. Divergências Conceituais em Torno da Comunicação Popular e Comunitária na América Latina. E-Compós, v. 9, 2007.

DOWNING, John D. H. Radical Media: Rebellious Communication and Social Movements. London: Sage, 2001.

ESTEVES, André. O Cidadão: Um jornal na era da globalização [Tese de Mestrado]. Rio de Janeiro: UFRJ/ECO, 2004.

FESTA, Regina; SILVA, Carlos E. Lins da (Orgs). Comunicação Popular e Alternativa no Brasil. São Paulo: Paulinas, 1986.

FRASER, Nancy. Rethinking the Public Sphere: A Contribution to the Critique of Actually Existing Democracy. In CALHOUN, Craig (Org.) Habermas and the Public Sphere. Cambridge: The MIT Press, 1992.

GILLMOR, Dan. We the Media: Grassroots Journalism by the People, for the People. Sebastopol: O’Reilly Media, 2004.

GUMUCIO-DAGRON, Alfonso. Haciendo Olas: Historias de Comunicación Participativa para el Cambio Social. New York: The Rockefeller Foundation. 2001.

GUSTAFSSON, Jessica. Community Radio as Promoters of Youth Culture. In TUFTE, Thomas; WILDERMUTH, Norbert; HANSEN-SKOVMOES, Anne Sofie; MITULLAH, Winnie (Orgs.). Speaking Up or Talking Back? Media, Empowerment and Civic Engagement Among East and Southern African Youth. Gotenburgo: NORDICOM, 2013.

HANUSCH, Folker. Indigenous Cultural Values and Journalism in the Asia-Pacific Region: A Brief History of Māori Journalism. Asian Journal of Communication, v. 24, n. 4, 2014. p. 390.

HOWLEY, Kevin. Community Media: People, Places, and Communication Technologies. New York: Cambridge. 2005.

LAUTERER, Jock. Community Journalism: Relentlessly Local. Chapel Hill: The University of North Carolina Press. 2006.

KARIKARI, Kwame. The Development of Community Media in English-Speaking West Africa. In: BOAFO, Kwame (Org.) Promoting Community Media in Africa, Paris: UNESCO, 2000.

LUKES, Steven. O Poder: uma Visão Radical. Brasília: Editora Universidade de Brasília, 1980.

MATSAGANIS, Mathew; KATZ, Vikky; BALL-ROKEACH, Sandra. Understanding Ethnic Media: Producers, Consumers, and Societies. London: Sage. 2011. 
MEADOWS, Michael. Electronic Dreaming Tracks: Indigenous Community Broadcasting in Australia. Development in Practice, v. 19, n.4-5, 2009. p. 514.

; MOLNAR, Hellen. Bridging The Gaps: Towards a History of Indigenous Media in Australia. Media History, v. 8, n. 1, 2002. p. 09.

; FORDE, Susan; EWART, Jacqui; FOXWELL, Kerry. A Catalyst for Change? Australian Community Broadcasting Audiences Fight Back. In: GORDON, Janey (Org.) Notions of Community: An Edited Collection of Community Media Debates. Bern: Peter Lang. 2009.

MORAES, Dênis de. Comunicação, Hegemonia e Contra-Hegemonia: a Contribuição Teórica de Gramsci. Revista Debates, v. 4, n. 1, pp. 54-77, 2010.

OJO, Tokunbo. Ethnic Print Media in the Multicultural Nation of Canada: A Case Study of the Black Newspaper in Montreal. Journalism, v. 7, n. 3, 2006.

PAIVA, Raquel. O Espírito Comum: Comunidade, Mídia e Globalismo. Rio de Janeiro: Mauad, 2003.

; CUSTÓDIO, Leonardo; MALERBA, João. "Comunidade Gerativa" e "Comunidade de Afeto": Propostas Conceituais para Estudos Comparativos de Comunicação Comunitária. Animus, v. 12, n. 24, 2013. p. 244.

PAVARALA, Vinod; MALIK, Kanchan. Other Voices: The Struggle for Community Radio in India. New Dehli: Sage, 2007.

PERLMAN, Janice. Favela: Four Decades of Living on the Edge in Rio de Janeiro. New York: Oxford University Press, 2010.

PERUZZO, Cicilia Maria Krohling. Comunicação nos Movimentos Populares: a Participação na Construção da Cidadania. Petrópolis: Editora Vozes, 1998.

Participation in Community Communication. In: SERVAES, Jan; JACOBSON, Thomas; WHITE, Shirley (Orgs.), Participatory communication for social change. London: Sage Publications, 2006.

Conceitos de Comunicação Popular, Alternativa e Comunitária Revisitados. Reelaborações no Setor. Palabra Clave, Bogotá, v. 11, n. 2, 2008. p. 367.

PLANSAK, Mojca; VOLCIC, Zala. Reimagining National Belonging with Community Radio. In: HOWLEY, Kevin (Org). Understanding Community Media. London: Sage, 2010.

READER, Bill; HATCHER, John A (Orgs.). Foundations of Community Journalism. Thousand Oaks: SAGE, 2012.

RODRIGUEZ, Clemencia. Fissures in the Mediascape: An International Study of Citizens' Media. Cresskill: Hampton Press, 2001.

Citizens' Media Against Armed Conflict: Disrupting Violence in Colombia. Minneapolis: University of Minnesota Press, 2001.

RODRIGUEZ, Clemencia; FERRON, Benjamin; SHAMAS, Kristin. Four Challenges in the Field of Alternative, Radical and Citizens' Media Research. Media, Culture \& Society, v. 36, 2014. p. 150.

SAEED, Saima. Negotiating Power: Community Media, Democracy, and the Public Sphere. Development in Practice, v. 19, n. 4-5, 2009. p. 466. 
SOUZA, Jessé. Ralé Brasileira: Quem é e Como Vive. Belo Horizonte: Editora UFMG, 2009.

TABING, Louie. The Development of Community Media in South-East Asia. In BOAFO, Kwame (Org.) Promoting Community Media in Africa. Paris: UNESCO, 2000.

TANAKA, Giselle Megumi Martino. Periferia: Conceito, Práticas e Discursos; Práticas Sociais e Processos Urbanos na Metrópole de São Paulo [Tese de Mestrado]. São Paulo: FAUUSP, 2006.

WANYEKI, L. Muthoni. The Development of Community Media in East and Southern Africa. In: BOAFO, Kwame (Org.) Promoting Community Media in Africa. Paris: UNESCO, 2000.

WARNER, Michael. Publics and counterpublics. Public Culture, v. 14, n. 1, 2002, p. 49-90. 